NOTE

\title{
Enhancement of red abalone Haliotis rufescens stocks at San Miguel Island: reassessing a success story
}

\author{
Ronald S. Burton ${ }^{1, *}$, Mia J. Tegner ${ }^{2}$ \\ ${ }^{1}$ Marine Biology Research Division and ${ }^{2}$ Marine Life Research Group, Scripps Institution of Oceanography, University of California, \\ San Diego, La Jolla, California 92093-0202, USA
}

\begin{abstract}
Outplanting of hatchery-reared juvenile abalone has received much attention as a strategy for enhancement of depleted natural stocks. Most outplants attempted to date appear to have been unsuccessful. However, based on genetic analyses of a population sample taken in 1992, it has recently been suggested that a 1979 outplanting of red abalone Haliotis rufescens, on the south side of San Miguel Island (California, USA), was successful and probably sustained the fishery there through the 1980s. We resampled the San Miguel population in 1999 and found no genetic signature of the outplants. Allelic frequencies in our 1999 sample closely resemble those observed in a pre-outplant 1979 southern California sample and two 1999 northern California populations. All genotypic frequencies were in Hardy-Weinberg expected proportions. We also assessed mtDNA diversity at San Miguel and found it not to differ from that of 2 robust northern California populations of $H$. rufescens. Our results suggest that either the composition of the San Miguel abalone population changed rapidly between 1992 and 1999, or the genetic anomalies attributed to hatchery source for the 1992 sample were due to sample degradation or other laboratory artifacts. Since we lack samples from the 1992 collections, we cannot directly test which explanation is valid. However, several lines of reasoning call into question the earlier conclusion of outplant success.
\end{abstract}

KEY WORDS: Abalone · Stock enhancement • Haliotis rufescens $\cdot$ San Miguel Island

Resale or republication not permitted without written consent of the publisher

As marine fishery stocks are depleted, efforts to enhance natural stocks via outplants of hatchery-reared seed continue to grow (Munroe \& Bell 1997). Such practices have long been routine in numerous fisheries (e.g., salmonid fish hatcheries and oyster farming) and are currently underway or under study for a diversity of heavily exploited species. Outplanting of hatcheryreared organisms for stock enhancement raises important issues: What are the potential genetic conse-

*E-mail: rburton@ucsd.edu quences of such practices? How can the success of costly outplants be assessed? Such questions point to conflicting needs regarding the genetic composition of outplanted organisms. Where large numbers of organisms are artificially released into a depleted population, substantial changes in the genetic composition of natural populations may occur (e.g., Tringali \& Bert 1998, Utter 1998). A variety of scenarios suggest that wholesale changes in genetic composition of natural populations may be undesirable at best and potentially disastrous. On the other hand, given the highly unpredictable nature of marine populations, rapid changes in stock sizes may be the result of outplanting activities or they may simply reflect natural fluctuations in population sizes. As outplant activities can be costly, methods for determining if enhanced stocks are the direct result of these operations are of great importance. Here, because genetic characters are transmitted to future generations, the idea of using genetically 'marked' individuals for outplanting appears to have great potential. However, this use of genetics may directly subvert attempts to minimize genetic alteration of natural stocks.

Because of their high market value and depressed natural populations (e.g., Shepherd \& Brown 1993, Haaker 1994), abalone outplanting has attracted considerable interest in various parts of the world. The California Department of Fish and Game and the California Sea Grant Program have conducted a variety of seeding experiments with hatchery-reared juvenile abalone in California (reviewed by Tegner \& Butler 1989, Tegner 2000). These experiments have generally not produced encouraging results. However, Gaffney et al. (1996) recently reported that the genetic composition of red abalone Haliotis rufescens collected from San Miguel Island (SMI) in 1992 strongly suggested that they were of hatchery origin. They concluded that the red abalone were derived from an outplant experi- 
ment conducted at Tyler Bight on SMI in 1979. That experiment was a major test of size-specific seed survivorship and Tyler Bight was selected because the habitat supported (and continues to support) a healthy red abalone population (Haaker 1994, Karpov et al. 2000). A total of 42431 red abalone seed ranging in size from 10 to $34 \mathrm{~mm}$ were released in August and October 1979. Unfortunately, most of the seed for this experiment came from a hatchery with recirculating seawater that caused severe shell erosion; many of the seed were fragile and shiny, making them susceptible to high predation pressure (Tegner \& Butler 1989).

Despite early indications that the Tyler Bight outplant was unlikely to be successful, Gaffney et al. (1996) suggest that it had, in fact, supported a significant fishery at SMI in the 1980s. Their inference regarding the outplant success was based primarily on 2 observations: (1) allelic frequencies at 2 allozyme loci (of 4 surveyed) in the SMI sample were significantly different from those observed in natural populations sampled in both northern and southern California, and (2) all individuals sampled at SMI were heterozygous for the same 2 alleles at the GPI (glucose-6-phosphate isomerase) locus, suggesting they originated from a hatchery rather than a natural population, which would likely show Hardy-Weinberg expected genotypic proportions. These results and conclusions have important implications. First, the results suggest that a 1979 outplant had dramatically altered the genetic composition of a natural population sampled $13 \mathrm{yr}$ later. Second, the fact that all red abalone collected at SMI in 1992 were GPI heterozygotes suggests that this population had experienced no natural recruitment to the fishery between 1979 and 1992 (since at least half the natural recruits would be expected to be homozygotes at GPI). Finally, the report suggests that red abalone outplanting has been successful and might, therefore, merit considerable funding support.

Given the importance of correctly assessing outplanting success, we initiated follow-up investigations of the SMI Haliotis rufesens population. Here we report results of a genetic analysis of red abalone collected from SMI in 1999, $7 \mathrm{yr}$ after the sampling reported by Gaffney et al. (1996) and 20 yr after the original outplanting.

Materials and methods. Sample collection: Haliotis rufesens were sampled from Tyler Bight to Crook Point on the south side of SMI in March 1999. This is the same region sampled by Gaffney et al. (1996). Unlike the other Channel Islands, SMI has continued to support healthy stocks of $H$. rufescens over much of its available habitat (P. L. Haaker, California Department of Fish and Game, unpubl. data), presumably because its greater distance from port and rougher seas at SMI reduce fishing pressure while its cooler ocean temper- atures buffer thermal stress during El Niño events (Tegner \& Dayton 1987). All of the sampled red abalone were sport legal $(178 \mathrm{~mm})$ size or larger; some were commercial size (197 mm). Sampling was nondestructive; divers detached each abalone from the substrate, pinched off an epipodial tentacle with a locking forceps, and returned the animal to the rock substrate. (Using this method, repeated sampling of abalone maintained in laboratory aquaria does not appear to harm the animals.) After surfacing, divers removed the samples from the forceps, placed them in individual $1.5 \mathrm{ml}$ microfuge tubes, and froze the tubes in liquid nitrogen for shipping. Once in the laboratory, samples were stored at $-80^{\circ} \mathrm{C}$. Samples of epipodial tissue from 2 northern California populations, Horseshoe Cove (HSC, southern Sonoma County, at Bodega Bay) and Shelter Cove (SH, southern Humboldt County), were kindly provided by C. Friedman (Bodega Marine Laboratory).

Protein electrophoresis: Electrophoretic analyses were conducted as described in Kordos \& Burton (1993), using $6 \%$ polyacrylamide slab gels $(0.75 \mathrm{~mm}$ thick) and enzyme staining by standard recipes (Harris \& Hopkinson 1976). Gels were run vertically in a continuous Tris-borate-EDTA buffer system $(\mathrm{pH}$ 8.9) at $10^{\circ} \mathrm{C}$ and $120 \mathrm{~V}$ for $4 \mathrm{~h}$. We attempted to score the same 4 loci as Gaffney et al. (1996); all but malic dehydrogenase $(\mathrm{MDH})$ yielded well-resolved bands on our gel system. Because MDH was only weakly polymorphic and therefore uninformative (Gaffney et al. 1996), it was omitted from the present study. The enzymes examined were: aspartate aminotransferase (the faster migrating of 2 loci, AAT1, EC 2.6.1.1 = GOT), phosphoglucomutase (PGM, EC 5.4.2.2) and glucose-6phosphate isomerase (GPI, EC 5.3.1.9). Interpopulation comparisons were facilitated by having multiple populations represented on each gel. Allozyme data were analyzed using the software package POPGENE 1.21 (Yeh \& Boyle 1997). Contingency tables (G-tests) were used to compare allelic counts for population differentiation and for tests of deviations from Hardy-Weinberg genotypic proportions. Levels of population subdivision were calculated using Wright's standardized variance in allelic frequencies $\left(F_{\mathrm{ST}}\right)$; significance of $F_{\mathrm{ST}}$ was determined using the methods described in Waples (1987).

Mitochondrial DNA analyses: DNA was extracted from approximately $6 \mathrm{mg}$ of tissue by incubation in $200 \mu \mathrm{l}$ of $10 \%$ chelating resin (Sigma) for $8 \mathrm{~min}$ at $100^{\circ} \mathrm{C}$. A $580 \mathrm{bp}$ fragment of the mitochondrial gene cytochrome oxidase subunit I (COI) was amplified using the polymerase chain reaction (PCR). Thermal cycler settings were: $3 \mathrm{~min}$ initial denaturation at $94^{\circ} \mathrm{C}$, 35 cycles at $95(1 \mathrm{~min}), 50(1 \mathrm{~min})$ and $72^{\circ} \mathrm{C}(1.5 \mathrm{~min})$, with a 7 min final extension at $72^{\circ} \mathrm{C}$. Abalone specific 
primers were designed by Metz et al. (1998): forward, 5' TGATCCGGCTTAGTCGGACTGC 3'; reverse, 3' GATGTCTTGAAATTACGGTCGGT 5'. PCR products were visualized on $2 \%$ agarose TAE (Tris-acetateEDTA). Reactions yielding sharp product bands were prepared for sequencing using the QIAquick PCR Purification Kit (Qiagen, Inc., Chatsworth, CA) and sequenced on an Applied Biosystems 373 Autosequencer using the Big Dye Terminator RR chemistry (Applied Biosystems) following manufacturer's protocols. Single stranded sequencing used the forward PCR primer. Sequences were aligned with Sequencher 3.1 (Genecodes Corp) and analyzed using PAUP 4.0b2 (Swofford 1999) and DnaSP Version 3.0 (Rozas \& Rozas 1999).

Results. Sample sizes and observed allozyme frequencies for the 1999 population samples are presented in Table 1; data from Gaffney et al. (1996) are included for comparison. First, considering only the 1999 samples, no significant deviations from HardyWeinberg expected genotypic proportions were observed at any of the 3 loci in any of the 3 sampled populations. Marginally significant genetic differentiation was apparent at the AAT1 locus (contingency table test of homogeneity of allelic counts, $\chi^{2}=12.51$, df $=6$, $\mathrm{p}=0.051$ ); no significant population heterogeneity was observed at the GPI or PGM loci. Calculated $F_{\text {ST }}$ values both at the individual loci $(0.016,0.006$, and 0.013 for AAT1, GPI and PGM respectively) and averaged across loci (0.012) did not differ significantly from zero.

When the new SMI-99 data are compared to SMI-92 data, significant differentiation is observed at 2 of the 3 loci $\left(\chi^{2}=40.8, p<0.001\right.$ for GPI, $\chi^{2}=14.0, p<0.001$ for AAT1). The AAT1 differentiation cannot be attributed to a hatchery source for SMI-92 abalone because SMI-
92 does not differ from the allelic frequencies observed in the SC-79 (from southern California) sample. In contrast, the SMI-92 GPI frequencies differ from those observed in all natural population samples. Again, the most striking observation regarding the SMI-92 GPI data concerns the total lack of homozygotes; all 1999 samples were dominated by homozygotes as expected from the observed allelic frequencies.

COI sequences (484 bp) were obtained from 20 abalone each from SMI and $\mathrm{SH}$, and 21 abalone from HSC (Table 2). Fifteen nucleotide sites were variable among the 61 sequences; all substitutions were synonymous. Only 7 nucleotide sites were informative; ignoring variation at uninformative sites (i.e., singletons), there are 7 different composite haplotypes (Table 2). All haplotypes observed more than twice were present in all 3 populations. Haplotypic diversity (including singletons) in the total sample was high

Table 2. Haliotis rufescens. Cytochrome oxidase subunit 1 haplotypes and their frequencies in 3 California populations. Base positions sequenced (484 bp) correspond to positions 37 to 520 in the Genbank sequence (AF060837) determined by Metz et al. (1998)

\begin{tabular}{|lcccc|}
\hline Haplotype & Position & \multicolumn{3}{c|}{ Population } \\
& $\begin{array}{l}11122 \\
9903433\end{array}$ & SMI & HSC & SH \\
& 6958417 & & & \\
\hline 1 & AAAAAAA & 8 & 5 & 5 \\
2 & AAAAAAG & 4 & 6 & 6 \\
3 & AGAAGAA & 3 & 5 & 6 \\
4 & AGAAGGA & 1 & 1 & 2 \\
5 & AAGAAAA & 0 & 1 & 0 \\
6 & GAGAAAA & 3 & 2 & 1 \\
7 & AAAGAAG & 1 & 1 & 0 \\
\hline
\end{tabular}

Table 1. Haliotis rufescens. Allozyme frequencies for 3 populations collected in 1999 compared to data reported in Gaffney et al. (1996). Allelic designations ( $a, b, c, d)$ reflect increasing anodal migration. Because different electraphoretic systems were employed, identities between this study and that of Gaffney et al. are only inferred from frequency data. n: number of individuals scored; SMI: San Miguel Island; HSC: Horseshoe Cove; SH: Shelter Cove; GPI: glucose-6-phosphate isomerase; PGM: phosphoglucomutase; AAT1: aspartate aminotransferase

\begin{tabular}{|c|c|c|c|c|c|c|c|c|c|c|c|c|c|c|c|c|c|}
\hline \multicolumn{2}{|c|}{ Population } & \multicolumn{3}{|c|}{ GPI } & \multirow[b]{2}{*}{ d } & \multirow[b]{2}{*}{$\mathrm{n}$} & \multirow[b]{2}{*}{ a } & \multicolumn{3}{|c|}{ PGM } & \multirow[b]{2}{*}{ e } & \multirow[b]{2}{*}{$\mathrm{f}$} & \multirow[b]{2}{*}{$\mathrm{n}$} & \multicolumn{3}{|c|}{ AAT1 } & \multirow[b]{2}{*}{$\mathrm{d}$} \\
\hline & $\mathrm{n}$ & $\mathrm{a}$ & $\mathrm{b}$ & $\mathrm{C}$ & & & & $\mathrm{b}$ & $\mathrm{C}$ & d & & & & a & $\mathrm{b}$ & $\mathrm{C}$ & \\
\hline \multicolumn{18}{|c|}{ Data from this study } \\
\hline SMI-99 & 46 & 0.913 & 0.076 & 0.011 & & 46 & & 0.033 & 0.076 & 0.674 & 0.207 & 0.011 & 43 & 0.174 & & 0.826 & \\
\hline HSC-99 & 30 & 0.883 & 0.100 & 0.017 & & 30 & & 0.133 & 0.067 & 0.517 & 0.267 & 0.017 & 30 & 0.067 & 0.033 & 0.883 & 0.017 \\
\hline SH-99 & 59 & 0.847 & 0.127 & 0.026 & & 55 & 0.009 & 0.100 & 0.073 & 0.618 & 0.200 & & 48 & 0.083 & & 0.906 & 0.010 \\
\hline \multicolumn{18}{|c|}{ Data from Gaffney et al. (1996) } \\
\hline SMI-92 & 60 & 0.500 & 0.500 & & & 60 & & & 0.008 & 0.775 & 0.217 & & 60 & 0.025 & & 0.975 & \\
\hline $\mathrm{NC}-92^{\mathrm{a}}$ & 116 & 0.884 & 0.108 & 0.004 & 0.004 & 116 & 0.004 & 0.009 & 0.129 & 0.543 & 0.315 & & 116 & 0.086 & & 0.914 & \\
\hline $\mathrm{SC}-79^{\mathrm{a}}$ & 208 & 0.858 & 0.132 & 0.007 & 0.002 & 192 & & 0.010 & 0.130 & 0.594 & 0.266 & & 84 & 0.030 & & 0.970 & \\
\hline
\end{tabular}


(0.83) and did not vary significantly across populations (extremes of $0.81 \pm 0.07$ at SMI to $0.87 \pm 0.04$ at HSC). Nucleotide diversity $(\pi)$ was also similar across populations, only ranging from $0.0042 \pm 0.0005$ at $\mathrm{SH}$ to $0.0046 \pm 0.0009$ at SMI. No significant differences in haplotypic frequencies were observed among populations and none of the pairwise $F_{\mathrm{ST}}$ analogues calculated by the DnaSP program (including Nei 1982, Lynch \& Crease 1990, and Hudson et al. 1992) were significantly different from zero.

Discussion. An experimental abalone enhancement program was established in California after a precipitous decline in landings began in the late 1960s (reviewed by Tegner 2000). This effort was modeled in part on the massive outplanting of hatchery-reared juveniles that has been conducted for many years in Japan (e.g., Ikenoue \& Kafuku 1992). Seeding experiments in California included 3 abalone species in a range of sizes, planting densities, and techniques; island and mainland sites in the southern, central, and northern regions of the state; and tests of a variety of devices designed to ease acclimation. Most of the studies were evaluated by extensive field surveys (although the data from the Tyler Bight experiment on SMI have not been analyzed). In each case, the estimated 1 or 2 yr survival rates based on the recovery of live seed was $2.8 \%$ or less.

Despite this low rate of success, several factors contribute to the continued appeal of outplanting of hatchery-reared abalones (Tegner 2000): (1) analogous programs with salmon and trout have been successful, (2) outplanting offers an alternative to restrictions on fishing effort, (3) outplanting is potentially much faster than natural recovery, and (4) outplanting could prove self-sustaining (Tegner \& Butler 1989). On the negative side, seeding hatchery-reared abalones may: (1) divert resources from needed management and assessment, (2) hinder harder decisions to reduce fishing effort to protect native stocks, (3) promote spread of disease or introduction of exotic parasites into wild populations (Kuris \& Culver 1999), and (4) result in loss of genetic diversity (Tringali \& Bert 1998). Although there is short-term evidence that seeding can prove effective in certain situations (Schiel 1993), the only long-term results are from Japan. The Japanese fishery has not collapsed like those in southern and central California, but the decline in landings from more than $6000 \mathrm{t}$ in the 1960s (Ikenoue \& Kafuku 1992) to $3000 \mathrm{t}$ despite ever increasing seeding (Uki 1989, Seki \& Sano 1998) is leading to a re-evaluation of abalone enhancement in that country. Given that the prospects of seeding were used to defer more painful restrictions on fishing effort in California in the 1970s (Tegner 2000), it is very important that evidence for enhancement be correct.
Although there are good reasons not to use rare genotypes in stock enhancement programs, lack of genetic tagging makes long-term evaluation of such efforts difficult. To date, no California outplants have been deliberately genetically tagged. The genetic anomalies reported by Gaffney et al. (1996) for their SMI-92 sample, however, are certainly suggestive of hatchery origin: both unusual allelic frequencies and large deviations from Hardy-Weinberg genotypic proportions could be indicative of a cohort of abalone derived from few female broodstock. However, in this particular case, the genetic signal was actually stronger than expected-given that broodstock were not genotyped before mating, it is difficult to construct the hatchery and natural population conditions that would produce a sample of 60 abalone with $100 \%$ heterozygosity at GPI. This observation initiated our interest in resampling the SMI population. As detailed above, our SMI-99 sample shows no evidence of the genetic characteristics that led Gaffney et al. (1996) to conclude that their 1992 SMI abalone were the result of a 1979 hatchery outplant. In fact, based on the scored marker loci, the SMI-99 sample closely resembles that reported for 1979 (pre-outplant) southern California and 1992 northern California red abalone.

There are at least 2 possible explanations for the differences in the 2 SMI data sets: (1) there was a dramatic change in the genetic composition of the SMI population in the $7 \mathrm{yr}$ between sampling dates (1992 to 1999), or (2) GPI was mis-scored in Gaffney et al. (1996), perhaps due to sample degradation or laboratory artifact. Since we are unaware of frozen archived tissues from SMI (dating from 1979 to 1992) that could be used for allozyme analyses, we cannot directly test either hypothesis. We raise the latter possibility because the data, as the authors admit, are difficult to explain. The probability that a hatchery could produce a set of all heterozygous offspring at GPI is small. Assuming that the hatchery broodstock came from California, the probability of such a single mating of alternate homozygotes is less than 0.03 (Gaffney et al. 1996). Furthermore, as Gaffney et al. (1996) note, the other loci studied indicate that the SMI cohort was the result of multiple parental pairs; the probability that several males were one homozygous type and several females were the other is negligible $\left([0.03]^{2}<0.001\right.$ for even 2 such pairs). Furthermore, the Gaffney et al. (1996) results suggest that essentially all red abalone sampled at SMI in 1992 were outplants, i.e., there was no natural recruitment to the fishery in this population (since over $75 \%$ of abalone in natural populations are GPI homozygotes). To account for the difference between the 1992 sample and our 1999 sample, the frequency of outplants at the site must have gone from near $100 \%$ to near zero in the $7 \mathrm{yr}$ period. Given that 
red abalone are long-lived (large abalone are probably well over 20 yr old; Morris et al. 1980), and that the outplants must have been extremely successful for $13 \mathrm{yr}$ in order to dominate the 1992 sample, this seems improbable.

An alternative explanation is that some laboratory artifact led to misscoring GPI in the SMI-92 sample. This possibility is raised by a similar situation in the literature. Cole \& Morgan (1978) scored nearly all individuals of the blue crab Callinectes sapidus, collected from 2 bays in Maryland, as GPI heterozygotes and reported frequencies of 0.45 and 0.55 for the 2 observed alleles. This level of GPI heterozygosity is inconsistent with other surveys of allozyme polymorphism of Atlantic coast C. sapidus (e.g., McMillenJackson et al. 1994) which have found that GPI is only weakly polymorphic over the entire Atlantic range of the species. Here again we cannot prove that an error in scoring occurred, but the large deviations from Hardy-Weinberg genotypic proportions in the suspect samples warrant cautious interpretations. In fact, 'subbanding' of unknown origin is common in GPI isozymes and it may well lead to misscoring since homozygote individuals can produce the 3 evenly spaced bands usually attributed to heterozygotes (e.g., see Fig. 14, p. 92, Murphy et al. 1996). In sum, it seems that GPI allozymes are susceptible to producing anomalous banding patterns on gels, perhaps due to partial degradation during sample storage.

Our mtDNA sequence data further support our conclusion that the SMI-99 sample lacks a genetic signature of outplant success. If red abalone at SMI derive from hatchery stocks, one might expect some reduction in mtDNA diversity if the number of broodstock were limited (as suggested from the GPI data). No evidence was found for such a reduction; mtDNA diversity at SMI is high and presently indistinguishable from that observed at HSC and SH, 2 northern California sites harboring robust natural populations of Haliotis rufescens.

Aside from genetic data, there are 2 further lines of reasoning that suggest that the Gaffney et al. (1996) conclusions were incorrect. First, the samples of Gaffney et al. (1996) were collected by commercial fishermen over $10 \mathrm{~km}$ of southern SMI, from Tyler Bight to Crook Point, whereas the seeding experiment was confined to Tyler Bight. Given the sedentary nature of abalones and large interspersed regions of sand in the rocky habitat, it is highly unlikely that experimental animals spread throughout this region to dominate these samples. A second issue concerns the sizes of the abalone in question. Red abalone growth rates are highly variable among years, reaching commercial size between 7.6 and 19.2 yr (Haaker et al. 1998). Given the severe growth depression observed during the 1982 to 1984 El Niño, it is unlikely that juveniles planted in 1979 entered the commercial fishery before the end of the 1980s.

Irrespective of the explanation for the genetic anomalies observed in the SMI-92 sample, the data presented here indicate that no genetic signature of outplants exists in the more recent SMI-99 sample. This, of course, does not mean that the outplant operation was unsuccessful. Since the outplants were not deliberately marked, there is no a priori reason to expect a genetic signature. Our conclusions, then, are simple: (1) there is no genetic evidence from our recent resampling of Haliotis rufescens from the south side of SMI that the 1979 outplant was successful, (2) previous genetic data reporting outplant success at this site are rather suspect, and (3) even if the outplant was successful up to the 1992 sampling, our data suggest that the success of the operation was limited to the growout period of the original outplants. Since red abalone can produce gametes at relatively small sizes (Morris et al. 1980), it is possible that outplanted abalone contributed to the local gene pool with a few years following the outplant. However, such a contribution is not evident. Had the outplants successfully reproduced and experienced some local recruitment, the frequency of the GPI ${ }^{b}$ allele should have shown some increase over time. Instead, the SMI-99 sample had the lowest frequency of this allele yet observed in a natural California population.

Previous efforts to assess the success of outplanting operations have frequently been ambiguous. The attempt by Gaffney et al. (1996) to use population genetics to infer outplant success clearly illustrates the potential of this approach. Obviously that work was hampered by a lack of data on the broodstock (or a sample of the outplant juveniles). Because adult abalone can easily be genotyped non-destructively, it will not be difficult to obtain multilocus genotypes using mtDNA and microsatellite loci (e.g., Kirby et al. 1998) of individual broodstock for future work. This will allow selection of unusual multilocus genotypes for production of juveniles for outplanting. By selecting broodstock with distinctive genotypes especially at marker loci that are likely to be selectively neutral (such as silent substitutions in DNA coding regions or length polymorphism in non-coding microsatellite loci), it should be possible to produce genetically marked outplant juveniles without greatly compromising their genetic diversity or fitness.

Finally, it should be noted that existing genetic data from the present study as well as those in Gaffney et al. (1996), Metz et al. (1998) and Kirby et al. (1998) suggest that there is not strong population divergence in Haliotis rufescens over its California range. The allozyme results presented here are consistent with pre- 
vious allozyme studies in abalone which have revealed only low levels of intraspecific population divergence (see review by Withler 2000). However, other types of genetic markers have revealed considerable variation in population structure in some abalone species. For example, Jiang et al. (1995) found fixed differences in mitochondrial DNA haplotypes between neighboring populations (35 km apart) of Taiwanese abalone $H$. diversicolor. The mtDNA data presented here for $3 \mathrm{H}$. rufescens populations spanning approximately $600 \mathrm{~km}$ of coastline suggest that this species does not exhibit such pronounced genetic differentiation. However, further studies examining additional populations and employing more genetic markers are needed to more thoroughly assess the genetic structure of this economically and ecologically important species.

Acknowledgements. We thank P. B. Edwards, C. S. Friedman, P. L. Haaker, and L. I. Vilchis for obtaining the samples, and the Pew Fellows Program in Marine Conservation for its financial support (to M.J.T.). We thank T. Ballard for laboratory assistance. The genetic analyses were completed under the sponsorship of the California Department of Fish and Game, Marine Resources Protection Act-Marine Ecological Reserves Research Program administered by California Sea Grant College System under grant number FG-5335MR, project number R/M-1 (RSB). Work was completed as of August 31, 1999 .

\section{LITERATURE CITED}

Cole MA, Morgan RP (1978) Genetic variation in two populations of the blue crab, Callinectes sapidus. Estuaries 1: 202-205

Gaffney PM, Rubin VP, Hedgecock D, Powers DA, Morris G, Hereford L (1996) Genetic effects of artificial propagation-signals from wild and hatchery populations of red abalone in California. Aquaculture 143:257-266

Haaker PL (1994) Assessment of abalone resources at the Channel Islands. In: Halvorson WL, Maender GJ (eds) The fourth California Islands symposium: update on the status of resources. Santa Barbara Museum of Natural History, Santa Barbara, CA, p 83-95

Haaker PL, Parker DO, Barsky KC, Chun CSY (1998) Growth of red abalone, Haliotis rufescens (Swainson), at Johnsons Lee, Santa Rosa Island, California. J Shellfish Res 17:747-753

Harris H, Hopkinson DA (1976) Handbook of enzyme electrophoresis in human genetics. North-Holland, Amsterdam

Hudson, RR, Slatkin M, Maddison WP (1992) Estimation of levels of gene flow from DNA sequence data. Genetics 132:583-589

Ikenoue H, Kafuku T (1992) Modern methods of aquaculture in Japan. Kodansha Ltd, Tokyo

Jiang L, Wu WL, Huang PC (1995) The mitochondrial DNA of Taiwan abalone Haliotis diversicolor Reeve, 1846 (Gastropoda: Archaeogastropoda: Haliotidae). Molec Mar Biol Biotechnol 4:353-364

Karpov KA, Haaker PL, Taniguichi I, Rogers-Bennett L (2000) Serial depletion and the collapse of the California abalone fishery. Can Spec Pub Fish Aquat Sci (in press)

Kirby VL, Villa R, Powers DA (1998) Identification of microsatellites in the California red abalone, Haliotis rufescens. J Shellfish Res 17:801-804

Editorial responsibility: Otto Kinne (Editor),

Oldendorf/Luhe, Germany
Kordos LM, Burton RS (1993) Genetic differentiation of Texas Gulf coast populations of the blue crab, Callinectes sapidus. Mar Biol 117:227-233

Kuris AM, Culver CS (1999) An introduced sabellid polychaete pest infesting cultured abalones and its potential spread to other California gastropods. Invertebr Biol 118: 391-403

Lynch M, Crease TJ (1990) The analysis of population survey data on DNA sequence variation. Mol Biol Evol 7:377-394

McMillen-Jackson AL, Bert TM, Steele P (1994) Population genetics of the blue crab,_Callinectes sapidus: modest population structuring in a background of high gene flow. Mar Biol 118:53-65

Metz EC, Robles-Sikisaka R, Vacquier VD (1998) Nonsynonymous substitution in abalone sperm fertilization genes exceeds substitution in introns and mitochondrial DNA. Proc Natl Acad Sci USA 95:10676-10681

Morris RH, Abbott DP, Haderlie EC (1980) Intertidal invertebrates of California. Stanford University Press, Stanford, CA

Munroe JL, Bell JD (1997) Enhancement of marine fisheries resources. Rev Fish Sci 5:185-222

Murphy RW, Sites JW Jr, Buth DG, Haufler CH (1996) Proteins: isozyme electrophoresis. In: Hillis DM, Moritz C, Mable BK (eds) Molecular systematics, 2nd edn. Sinauer Associates, Sunderland, MA, p 51-120

Nei M (1982) Evolution of human races at the gene level. In: Bonne-Tamir B, Cohen T, Goodman RM (eds) Human genetics, Part A: The unfolding genome. Alan R Liss, New York, p 167-181

Rozas J, Rozas R (1999) DnaSP version 3: an integrated program for molecular population genetics and molecular evolution analysis. Bioinformatics 15:174-175

Schiel DR (1993) Experimental evaluation of commercialscale enhancement of abalone Haliotis iris populations in New Zealand. Mar Ecol Prog Ser 97:167-181

Seki T, Sano M (1998) An ecological basis for the restoration of Japanese abalone populations. Bull Tohoku Natl Fish Res Inst 60:23-40 (in Japanese with English abstract)

Shepherd SA, Brown LD (1993) What is an abalone stock: implications for the role of refugia in conservation. Can J Fish Aquat Sci 50:2001-2009

Swofford DL (1999) PAUP (Phylogenetic Analysis using Parsomony) version 4. Sinauer Associates, Sunderland, MA

Tegner MJ (2000) Abalone (Haliotis spp.) enhancement in California: what we've learned and where we go from here. Can Spec Pub Fish Aquat Sci (in press)

Tegner MJ, Butler RA (1989) Abalone seeding. In: Hahn K (ed) Handbook of culture of abalone and other marine gastropods. CRC Press, Boca Raton, FL, p 157-182

Tegner MJ, Dayton PK (1987) El Niño effects on southern California kelp forest communities. Adv Ecol Res 17:243-279

Tringali MD, Bert TM (1998) Risk to genetic effective population size should be an important consideration in fish stock-enhancement programs. Bull Mar Sci 62:641-659

Uki N (1989) Abalone seeding production and its theory, Parts 1-3. Int J Aquat Fish Tech 1:3-15, 125-132, 224-231

Utter F (1998) Genetic problems of hatchery-reared progeny released into the wild and how to deal with them. Bull Mar Sci 62:623-640

Waples RS (1987) A multispecies approach to the analysis of gene flow in marine shore fishes. Evolution 41:385-400

Withler RE (2000) Genetic tools for identification and conservation of exploited abalone species. Can Spec Pub Fish Aquat Sci (in press)

Yeh FC, Boyle TJB (1997) Population genetic analysis of codominant and dominant markers and quantitative traits. Belg J Bot 129:157

Submitted: February 23, 2000; Accepted: June 8, 2000

Proofs received from author(s): July 24, 2000 